\section{SURGICAL TREATMENT OF PATIENTS WITH WOLFF- PARKINSON-WHITE SYNDROME AND ASSOCIATED EBSTEIN'S ANOMALY}

Ebstein's anomaly is the most common congenital heart disease associated with the Wolff-Parkinson-White syndrome. Between November 1973 and March 1993, we surgically treated 42 patients with Wolff-Parkinson-White syndrome and Ebstein's anomaly. The patients' ages ranged from 5 months to 59 years (mean $35.3 \pm 14.0$ years). There were a total of 52 accessory pathways, 48 of which were located in the right $(65 \%)$ or posteroseptal (29\%) area. A left-sided accessory pathway was seen in only two patients $(3.8 \%)$. Division of all right-sided accessory pathways was done during normothermic cardiopulmonary bypass with the heart beating; cryocoagulation was applied together with scalpel dissection of the atrioventricular groove. Division of the left-sided accessory pathways was done with the use of cold potassium cardioplegic arrest. Thirty-five of these patients underwent tricuspid valve operation for Ebstein's anomaly and 11 of them underwent tricuspid valve replacement with a bioprosthesis. All 52 accessory pathways were successfully divided, although two patients required reoperation because of tachycardia caused by accessory pathways in different positions. Three hospital deaths $\mathbf{( 7 . 1 \% )}$ occurred. There were no late deaths during the follow-up period (mean $94.3 \pm 52.4$ months), but two patients required repeat tricuspid operation because of progression of the tricuspid regurgitation. Because no repeat operations were required during long-term follow-up in patients who underwent valve repair or valve replacement, correction should be indicated in some patients. (J THORAC CARDIOVASC SurG 1995;110:1702-7)

Takuro Misaki, MD, ${ }^{\mathrm{a}}$ Go Watanabe, MD, ${ }^{\mathrm{a}}$ Takashi Iwa, MD,

Yoh Watanabe, MD, ${ }^{\mathrm{b}}$ Keiichi Mukai, MD, ${ }^{\mathrm{b}}$ Masao Takahashi, MD,

Hiroshi Ohtake, MD, ${ }^{b}$ and Keiichi Yamamoto, MD, ${ }^{a}$

Toyama and Kanazawa, Japan
$E_{c a d}^{\text {bes }}$ stein's anomaly is the most common congenital cardiac anomaly associated with Wolff-Parkinson-White (WPW) syndrome. ${ }^{1}$ The clinical course in patients with this combination is diverse and depends on the degree of severity of Ebstein's anomaly and associated arrhythmias. ${ }^{2}$ Concerning this pathologic combination ${ }^{3-9}$ there have been several electrophysiologic and surgical reports including those by Danielson and colleagues ${ }^{10}$ and Press-

From the Department of Surgery (1), Toyama Medical and Pharmaceutical University, Toyama, ${ }^{a}$ and the Department of Surgery (1), Kanazawa University School of Medicine, Kanazawa, ${ }^{\mathrm{b}}$ Japan.

Received for publication Feb. 10, 1994.

Accepted for publication April 6, 1995.

Address for reprints: Takuro Misaki, MD, Department of Surgery (1), Toyama Medical and Pharmaceutical University, Sugitani Toyama 2630, 930-01 Japan.

Copyright (C) 1995 by Mosby-Year Book, Inc.

$0022-5223 / 95 \$ 5.00+0 \quad \mathbf{1 2 / 1 / 6 5 3 3 3}$ ley and colleagues, ${ }^{11}$ but the long-term results of surgical treatment for this combination remain unclear. The purpose of this study was to evaluate the surgical treatment in 42 patients who were followed up for up to 20 years to extend our initial observations regarding this combination. ${ }^{12}$

\section{Patients and methods}

Between November 1973 and March 1993, 455 patients underwent surgical division of the accessory pathway (ACP) for treatment of WPW syndrome at our institutes (Kanazawa University School of Medicine and Toyama Medical and Pharmaceutical University): Of these patients, 42 had associated Ebstein's anomaly. The patients" ages ranged from 5 months to 59 years (mean $35.3 \pm 14.0$ years). The findings in these 42 patients were compared with those in the 413 patients without Ebstein's anomaly. The type and history of arrhythmias and number and location of ACPs, as well as the effective refractory period of antegrade ACPs, cycle length of reentrant tachycardias, and the shortest $R-R$ interval during atrial fibrillation, were routinely examined (Table I). Fourteen patients 
Table I. Patient characteristics and electrophysiologic features

\begin{tabular}{|c|c|c|c|}
\hline & \multicolumn{2}{|c|}{ Ebstein's anomaly } & \multirow[b]{2}{*}{$p$ Value } \\
\hline & Present $(n=42)$ & Absent $(n=413)$ & \\
\hline Mean age at operation (yr) & $35.3 \pm 14.0$ & $37.5 \pm 16.0$ & NS \\
\hline Duration of arrhythmia (yr) & $15.5 \pm 12.1$ & $12.4 \pm 10.7$ & NS \\
\hline History of cardiac arrest & $3(7.1 \%)$ & $11(2.7 \%)$ & NS \\
\hline History of direct cardioversion & $17(40 \%)$ & $127(31 \%)$ & NS \\
\hline Documented AF & $24(57 \%)$ & $222(54 \%)$ & NS \\
\hline Postoperative AF & $2(5.2 \%)$ & $42(10 \%)$ & NS \\
\hline Documented AVRT & $38(91 \%)$ & $357(87 \%)$ & NS \\
\hline Shortest $\mathrm{R}-\mathrm{R}$ interval during $\mathrm{AF}$ (msec) & $216 \pm 42$ & $227 \pm 51$ & NS \\
\hline ERP of antegrade ACP (msec) & $284 \pm 37$ & $276 \pm 42$ & NS \\
\hline Mean cycle length during AVRT (msec) & $344 \pm 58$ & $330 \pm 57$ & NS \\
\hline Multiple pathways & $10(24 \%)$ & $35(8.5 \%)$ & $<0.01$ \\
\hline Total number of ACPs & 52 & 451 & \\
\hline \multicolumn{4}{|l|}{ Location of ACP } \\
\hline Left & $2(3.8 \%)$ & $267(59 \%)$ & $<0.01$ \\
\hline Posteroseptal & $15(29 \%)$ & $48(11 \%)$ & $<0.01$ \\
\hline Right & $33(63 \%)$ & $124(27 \%)$ & $<0.01$ \\
\hline Anteroseptal & $2(3.8 \%)$ & $12(2.7 \%)$ & NS \\
\hline
\end{tabular}

$A F$, Atrial fibrillation; $A V R T$, atrioventricular tachycardia; $E R P$, effective refractory period.

(33\%) with mild Ebstein's anomalies had New York Heart Association (NYHA) functional class I or II symptoms. In 12 of these patients, the Ebstein's anomaly was not suspected by the physicians who referred the patients to us and mild anomaly was diagnosed in our institution during the preoperative echocardiographic assessment. Twentyeight patients $(67 \%)$ had moderate to severe Ebstein's anomaly with NYHA class III or IV symptoms and all of them had moderate or severe tricuspid regurgitation.

Surgical technique. After a median sternotomy, epicardial mapping was done to estimate the location of the ACP. ${ }^{13}$ Division of all right-sided ACPs, including those in the posterior septum, was done during normothermic cardiopulmonary bypass with the heart beating. Before a right atriotomy was done, the heart was briefly fibrillated to obtain closure of a patent foramen ovale or an atrial septal defect. The heart was then defibrillated, and a supraannular atrial incision was made $2 \mathrm{~mm}$ above the true anulus of the tricuspid valve. The supraannular atrial incisions for the right posterior or posteroseptal ACPs were extended from the coronary sinus to the anteroinferior commisure of the tricuspid valve. Dissection was done between the underlying fat tissue and the ventricular muscle. Closure of the atrial incision, tricuspid valvular operation, and division of left-sided ACPs were done with the use of cold potassium cardioplegic arrest.

Of the 35 patients who underwent tricuspid valve operation for Ebstein's anomaly (Table II), 24 underwent Hardy's procedure: tricuspid valve repair and plications of atrialized right ventricles., 14 The other 11 patients underwent tricuspid valve replacements; a Hancock porcine bioprosthesis* was used in five patients and a CarpentierEdwards bioprosthesis $\uparrow$ in six. Warfarin anticoagulation was initiated after removal of the chest tube. All patients

*Johnson \& Johnson Cardiovascular, King of Prussia, Pa. $\dagger$ †axter Healthcare Corp., Edwards Division, Santa Ana, Calif.
Table II. Surgical procedures $(n=42)$

\begin{tabular}{cc}
\hline & No. \\
\hline Division of accessory pathway & 42 \\
Repeat ACP division & 2 \\
Tricuspid valve operation & 35 \\
Hardy's procedure* & 24 \\
Tricuspid valve replacement & 11 \\
Additional procedure & 19 \\
Closure of ASD & 10 \\
Closure of PFO & 8 \\
Replacement of ascending & 1 \\
aorta and aortic valve replacement & \\
\hline
\end{tabular}

$A S D$, Atrial septal defect; $P F O$, persistent foramen ovale.

*Tricuspid valve repair with plication of atrialized right ventricle.

received warfarin for up to 3 months after implantation and thereafter it was discontinued.

Other associated cardiovascular abnormalities were observed in 19 patients, and those were corrected simultaneously. The procedures included 10 closures of secondum-type atrial septal defect, 8 closures of patent foramen ovale, and one replacement of the aortic valve and ascending aorta. ${ }^{1.5}$

Patient follow-up was done by maintaining direct contact with them or with their physicians. Follow-up was available for all patients, resulting in a $100 \%$ rate of completion.

Statistical methods. Data are expressed as mean plus or minus standard deviation. Univariate analysis was done with Student's $t$ test and $\chi^{2}$ test was used for comparison between groups. The probability of various factors influencing coexistence of Ebstein's anomaly was assessed by logistic regression analysis. Actuarial curves for event-free survival and death were generated by the method of Kaplan and Meier. The influence of various factors on risk 
Table III. Results of logistic regression analysis for coexistence of Ebstein's anomaly

\begin{tabular}{lcccc} 
& & \multicolumn{2}{c}{$95 \%$ Confidence limits } & \\
\cline { 3 - 5 } \multicolumn{1}{c}{ Variables } & Odds ratio & Lower & Upper & \\
\hline AVRT & 1.560 & 0.497 & 4.895 & 0.46 \\
Duration of arrhythmia & 1.034 & 1.005 & 1.064 & 0.02 \\
History of cardiac arrest & 3.095 & 0.719 & 13.326 & 0.13 \\
History of DC & 1.319 & 0.641 & 2.715 & 0.45 \\
No. of ACPs & 2.264 & 1.105 & 4.639 & 0.03 \\
\hline
\end{tabular}

$A V R T$, Atrioventricular tachycardia; $D C$, direct cardioversion.

of mortality was assessed by the Cox proportional hazards model. Odds ratios were quoted with $95 \%$ confidence intervals, with statistical significance at at least the $5 \%$ level being inferred.

\section{Results}

Clinical electrophysiologic characteristics. There was no significant difference in the clinical and electrophysiologic characteristics between the patients with and without Ebstein's anomaly (Table I). ACP distribution is also shown in this table. In the group of patients with Ebstein's anomaly, 10 patients $(24 \%)$ had multiple pathways. Of 52 ACPs, 48 were located in the right (65\%) or right posteroseptal $(29 \%)$ area, whereas left-sided, right lateral, or right anteroseptal ACPs were seen in only two patients $(3.8 \%)$. In patients without Ebstein's anomaly the most common location of ACPs was the left side. The difference in these distribution patterns between the patient groups was statistically significant.

Multivariate logistic analysis demonstrated that the odds ratios of two factors, duration of arrhythmia and number of ACPs, were significant, suggesting their relevance to Ebstein's anomaly associated with WPW syndrome (Table III).

Early surgical results. In the patients with Ebstein's anomaly, three hospital deaths $(7.1 \%)$ occurred. The cause of death in two patients, 40 and 57 years old, respectively, with preoperative NYHA class IV symptoms, was low cardiac output after division of ACPs and tricuspid valve replacement. The remaining death occurred in a 38 -year-old woman with a history of open cardiac massage necessitated by cardiac arrest. She died 22 days after tricuspid valve replacement of occult cancer (histiocytoma) refractory to chemotherapy. In these three patients, both delta waves and atrioventricular reentrant tachycardia had disappeared postoperatively.

Late surgical results. All of the remaining patients were followed up. No late deaths occurred during the mean follow-up interval (mean $94.3 \pm$ 52.4 months). During this period, four patients required a repeat cardiac operation. In two patients, reoperations were done because of recurrence of tachycardia caused by residual second ACPs 6 years and 4 months and 5 years and 1 month, respectively, after initial division of the ACPs. These ACPs were located in a different position from the initial ACPs. In one of the patients, plication was done because of mild tricuspid regurgitation in addition to second ACP division. Another patient, who initially had mild preoperative tricuspid regurgitation, required a tricuspid valve replacement 1 year and 7 months after the initial operation because of severe hypoproteinemia caused by progressive tricuspid regurgitation. The remaining patient required aortic valve replacement because of infective endocarditis 5 years and 1 month after the initial operation.

Eleven patients underwent tricuspid valve replacement with a xenograft because of tricuspid valve insufficiency caused by severe Ebstein's anomaly. During the follow-up period (mean $93.4 \pm 59.4$ months), no valve dysfunction, bleeding complication, or thromboembolic complication was noted and no reoperations were done.

Although two patients required reoperation because of tachycardia, after operation no recurrence of reentrant tachycardia was observed in any of the 39 patients. The postoperative prevalence of atrial fibrillation $(5.1 \%, 2 / 39)$ was significantly decreased compared with the preoperative incidence $(55 \%$, 23/42). There were no patients with new atrial fibrillation. All 39 patients were free from the need for antiarrhythmic drugs and had functional class I or II symptoms at the time of the most recent follow-up.

Results of Kaplan-Meier analysis of overall survival probability in patients with and without Ebstein's anomaly from the time of operation are shown in Fig. 1. Factors that influenced overall mortality are shown in Table IV. Multivariate Cox 


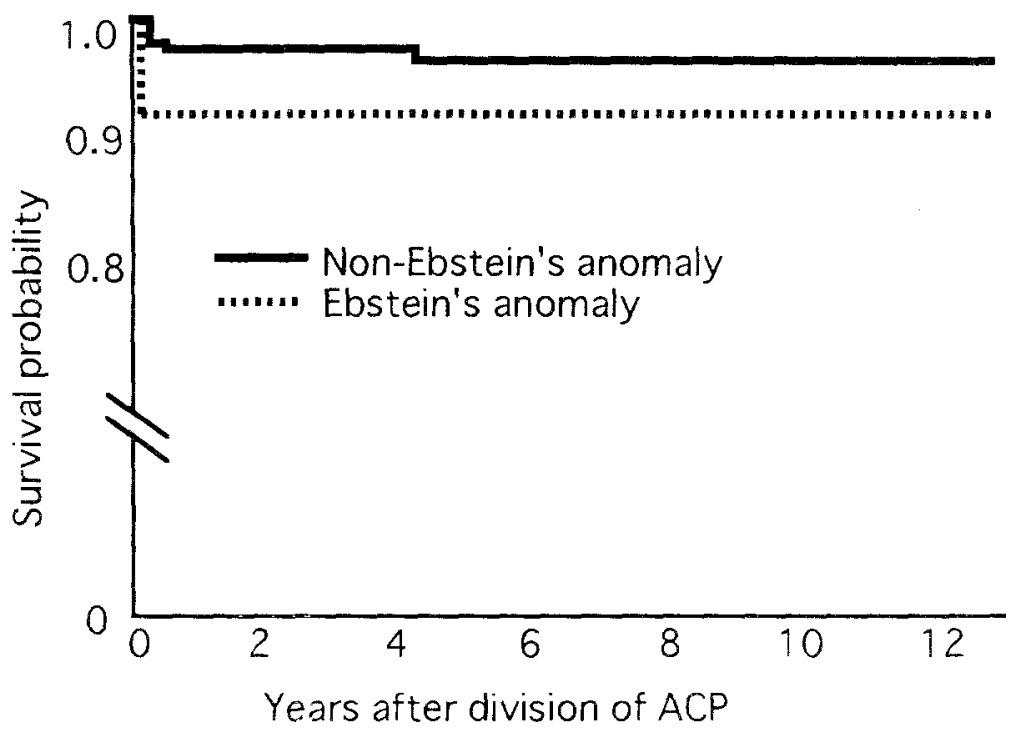

Fig. 1. Results of Kaplan-Meier analysis of overall survival probability from time of operation.

Table IV. Results of Cox regression analysis for factors predictive of overall mortality

\begin{tabular}{|c|c|c|c|c|}
\hline \multirow[b]{2}{*}{ Variables } & \multirow[b]{2}{*}{ Odds ratio } & \multicolumn{2}{|c|}{$95 \%$ Confidence limits } & \multirow[b]{2}{*}{$p$ Value } \\
\hline & & Lower & Upper & \\
\hline Age & 0.992 & 0.952 & 1.034 & 0.70 \\
\hline Combined disease & 0.254 & 0.024 & 2.656 & 0.25 \\
\hline AVRT & 2.739 & 0.296 & 25.331 & 0.38 \\
\hline $\mathrm{AF}$ & 1.869 & 0.387 & 9.021 & 0.44 \\
\hline History of cardiac arrest & 2.656 & 0.268 & 26.294 & 0.40 \\
\hline History of DC & 1.247 & 0.322 & 4.831 & 0.75 \\
\hline No. of ACPs & 1.964 & 0.494 & 7.806 & 0.34 \\
\hline Combined operation & 6.866 & 1.650 & 28.569 & 0.01 \\
\hline
\end{tabular}

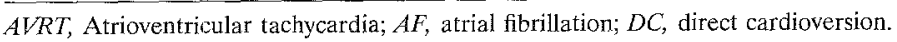

analysis demonstrated that combined operation was a significant predictor of death.

\section{Discussion}

Location of ACPs. In this study, we documented the electrophysiologic characteristics of ACPs in patients with Ebstein's anomaly. In our patients, $92 \%(48 / 52)$ of ACPs were located on the right side or in the posteroseptal area. This finding is consistent with the hypothesis that Ebstein's anomaly originates from the incomplete separation of the right atrium and right ventricle during cardiogenesis. ${ }^{16}$ Therefore it is possible that any part of the atrialized ventricle can be connected to the right atrium across the true anulus. This predominance of right posterior and right posteroseptal ACPs in patients with Ebstein's anomaly has been previously reported by $u s^{15}$ and Smith and associates. ${ }^{8}$ This finding may have clinical implications in terms of the selection of the surgical procedure. We performed complete detachment of the atrialized ventricle with use of a relatively large incision along the true anulus. $^{8}$

Multiple ACPs. In 1980 we reported a case of successful simultaneous operation for WPW syndrome in a patient with multiple ACPs and tricuspid valve replacement. ${ }^{7}$ We observed multiple ACPs in $24 \%$ of the patients with Ebstein's anomaly, which was more frequent than in patients without $\mathrm{Eb}$ stein's anomaly. A high prevalence of multiple ACPs is another electrophysiologic characteristic of this combination. In the patients of Pressley and associates, ${ }^{11}$ multiple ACPs were observed at a much higher rate $(50 \%)$ than in our patients. In our series, left-sided ACP was observed in two patients and accompanied one of the cases of multiple ACPs. Left-sided ACP is quite rare in patients with Ebstein's anomaly. ${ }^{11,17}$ 
Atrial fibrillation. The propensity for atrial fibrillation is suspected to be increased in patients with combined heart disease. ${ }^{15}$ However, in our series there was no significant difference between patients with and without Ebstein's anomaly in the percentage of atrial fibrillation or the shortest preexcited $\mathrm{R}-\mathrm{R}$ interval during atrial fibrillation. It is believed that these features may reflect the inclusion of patients at high risk with atrial fibrillation in this study. It is suggested that some degenerative changes of the atrium may be present in patients with Ebstein's anomaly. These observations are in accordance with the results described in the previous report. ${ }^{11}$

Mild Ebstein's anomaly and sudden cardiac arrest. Three of our patients had histories of sudden cardiac arrest. However, this rate was not significantly different from that in the patients without Ebstein's anomaly who underwent operation for WPW. Two of the patients with histories of sudden cardiac arrest had associated mild Ebstein's anomaly that did not necessitate any additional operation. Rossi and Thiene ${ }^{18}$ have reported similar cases of mild Ebstein's anomaly associated with sudden cardiac arrest. None of our patients with mild Ebstein's anomaly had significant hemodynamic alterations during sinus rhythm attributable to the malformation itself. Therefore, when nonpharmacologic procedures for this life-threatening arrhythmia are done it should be taken into consideration that patients with mild Ebstein's anomaly are at risk for the same severe arrhythmogenic events as patients with the classic forms of Ebstein's anomaly. Because unusual progression of tricuspid regurgitation was observed in three patients, a potential risk of reoperation was suggested.

Early mortality. In our patients, the surgical mortality rate was $7.1 \%(3 / 42)$. This indicates that a result comparable to that for patients with Ebstein's anomaly $(5.3 \% \text { to } 25 \%)^{10,11,19}$ was safely achieved in patients with Ebstein's anomaly associated with WPW syndrome. All three of the patients who died were in a relatively high age group (mean age 45 years), required tricuspid valve replacement, and had severely deteriorated preoperative cardiac function (NYHA class IV). The cause of death was thought to have been related not to the division of ACPs, but rather to the severity of the Ebstein's anomaly itself. These data suggest that early surgical intervention should be considered for patients with severe Ebstein's anomaly.

Long-term survival and morbidity. Excellent longterm results were obtained in our patients. The late mortality rate after operation for patients with Ebstein's anomaly has been reported to range from $5.6 \%$ to $15 \% .^{10,11,19}$ The causes of death in these patients were sudden death and uncontrolled arrhythmias. As stated, two of our patients required repeat tricuspid valve operation because of progression of tricuspid insufficiency caused by Ebstein's anomaly. Because no repeat operation has been required during long-term follow-up in patients who underwent tricuspid valve repair or valve replacement at operation, correction of tricuspid regurgitation might be indicated in some patients. Currently, such patients might be treated by catheter ablation and followed up carefully for possible progression of tricuspid regurgitation.

We thank Dr. K. Hashimoto, professor of the Department of Hygiene, Kanazawa University School of Medicine, and Dr. Y. Naruse, associate professor of the Department of Hygiene, Toyama Medical and Pharmaceutical University, for help in the statistical analysis.

\section{REFERENCES}

1. Porter CJ, Holmes DR. Preexcitation syndromes associated with congenial heart disease. In: Benditt DG, Benson DW, eds. Cardiac preexcitation syndromes: origins, evaluation and treatment. Boston: Martinus Nijhoff, 1986:291-301.

2. Marir DD. Ebstein's anomaly: natural history and management. J Am Coll Cardiol 1992;19:1047-8.

3. McFaul RC, Davis Z, Giuliani ER, Ritter DG, Danielson GK. Ebstein's malformation: surgical experience at the Mayo Clinic. J Thorac CardovasC SURG 1976;72:919-25.

4. Iwa T, Misaki T, Tsuchiya K. Surgery of WolffParkinson-White syndrome. In: Kelly DT, ed. Advances in the management of arrhythmias. Sydney: Telectronics, 1978:137-49.

5. Sealy WC, Gallagher JJ, Pritchett ELC, Wallace AG. Surgical treatment of tachyarrhythmias in patients with both an Ebstein's anomaly and a Kent bundle. J Thorac Cardiovasc Surg 1978;75:847-53.

6. Kugler JD, Gillette PC, Duff DF, Cooley DA, McNamara DG. Elective mapping and surgical division of Kent in a patient with Ebstein's anomaly who requires tricuspid valve replacement. Am J Cardiol 1978;41:602-5.

7. Iwa T, Teranaka M, Tsuchiya K, Misaki T, Watanabe Y. Simultaneous surgery for Wolff-Parkinson-White syndrome combined with Ebstein's anomaly: interruption of multiple accessory conduction pathways. Thorac Cardiovasc Surg 1980;28:42-7.

8. Smith WM, Gallagher JJ, Kerr CR, et al. The electrophysiologic basis and management of symptomatic 
recurrent tachycardia in patients with Ebstein's anomaly of the tricuspid valve. Am J Cardiol 1982;49:1223-34.

9. Misaki T, Iwa T, Mukai K, Matsunaga Y, Kamata E, Mitsui T. Surgical treatment of WPW syndrome with Ebstein's anomaly. J Jpn Assoc Thorac Surg 1986;34: $1735-43$.

10. Danielson GK, Driscoll DJ, Mair DD, Warnes CA, Oliver Jr WC. Operative treatment of Ebstein's anomaly. J THorac Cardiovasc SuRG 1992;104:1195-202.

11. Pressley JC, Wharton JM, Tang ASL, Lowe JE, Gallagher JJ, Prystowsky EN. Effect of Ebstein's anomaly on short- and long-term outcome of surgically treated patients with Wolff-Parkinson-White syndrome. Circulation 1992;86:1147-55.

12. Iwa $T$, Kawasuji M, Misaki $T$, Iwase $T$, Magara $T$. Localization and interruption of accessory conduction pathway in the Wolff-Parkinson-White syndrome. J Thorac Cardiovasc Surg 1980;80:271-9.

13. Iwa $T$, Mukai $K$, Misaki $T$, Mitsui $T$, Magara $Y$. Surgical management of the Wolff-Parkinson-White syndrome. In: Iwa $\mathrm{T}$, Fontaine $\mathrm{G}$, eds. Cardiac arrhythmias: recent progress in investigation and management. Amsterdam: Elsevier, 1988:239-50.
14. Hardy KL, May IA, Webster CA, Kimball KG. Ebstein's anomaly: a functional concept and successful definitive repair. J THORAC CARDIOvasC Surg 1964; 48:927-40.

15. Misaki T, Watanabe G, Iwa $T$, et al. Surgical treatment of patients with Wolff-Parkinson-White syndrome and associated acquired valvular heart disease. J THORAC CARDIOVASC SURG 1994;108:68-72.

16. Anderson KR, Zuberbuhler JR, Anderson RH, Becker AE, Lie JT. Morphologic spectrum of $\mathrm{Eb}$ stein's anomaly of the heart: a review. Mayo Clin Proc 1979;54:174-80.

17. Becker AE, Anderson RH, Durrer D, Wellens HJJ, The anatomical structures of Wolff-Parkinson-White syndrome: a clinicopathologic correlation in seven patients. Circulation 1978;57:870-9.

18. Rossi L, Thiene G. Mild Ebstein's anomaly associated with supraventricular tachycardia and sudden death: clinicomorphologic features in three patients. Am J Cardiol 1984;53:332-4.

19. Westaby S, Karp RB, Kirklin JW, Waldo AL, Blackstone EH. Surgical treatment in Ebstein's malformation. Ann Thorac Surg 1982;34:388-95.

\section{Availability of JournaL back issues}

As a service to our subscribers, copies of back issues of THE Journal of THORAcic AND CARdiovascular SURGERY for the preceding 5 years are maintained and are available for purchase from the publisher, Mosby-Year Book, Inc., at a cost of $\$ 12.00$ per issue. The following quantity discounts are available: $25 \%$ off on quantities of 12 to 23 , and one third off on quantities of 24 or more. Please write to Mosby- Year Book, Inc., Subscription Services, 11830 Westline Industrial Drive, St. Louis MO 63146-3318, or call (800) 453-4351 or (314) 453-4351 for information on availability of particular issues. If unavailable from the publisher, photocopies of complete issues are available from University Microfilms International, 300 N. Zeeb Rd., Ann Arbor, MI 48106 , (313) $761-4700$. 